\title{
Muscle Agrin: Neural Regulation and Localization at Nerve-induced Acetylcholine Receptor Clusters
}

\author{
Erich Lieth and Justin R. Fallon \\ Neurobiology Group, Worcester Foundation for Experimental Biology, Shrewsbury, Massachusetts 01545
}

\begin{abstract}
The synapse-organizing protein agrin is expressed by muscle cells. In this study we begin to characterize the role of muscle agrin in synapse formation by investigating its distribution and expression during the formation of nerve-induced $A C h$ receptor (AChR) aggregates in vitro. We have used species-specific anti-agrin antibodies to show that muscle agrin colocalizes with nerve-induced AChR clusters in chimeric nerve-muscle cocultures. Furthermore, quantitation by radioimmune assay shows that the expression of muscle agrin by cultured chick myotubes is increased more than twofold by coculture with cells from the motoneuronrich ventral spinal cord. These data suggest a role for muscle agrin in neuromuscular junction development.

[Key words: agrin, neuromuscular junction, synaptogenesis, extracellular matrix, basal lamina, nerve-muscle coculture, ACh receptor]
\end{abstract}

The organization of specific molecules at the postsynaptic membrane is one of the crucial processes in neuromuscular junction formation. Agrin, a protein present in the synaptic basal lamina of species ranging from fish (Fallon et al., 1985) to birds and mammals (Reist et al., 1987; Rupp et al., 1991), induces the redistribution of a number of synaptic molecules, such as $\mathrm{ACh}$ receptors (AChRs), into structures resembling postsynaptic specializations on myotubes in vitro (Nitkin et al., 1987; Wallace, 1989; Nastuk and Fallon, 1993).

Several lines of evidence support the hypothesis that agrin directs the formation of neuromuscular junctions. For instance, anti-agrin antibodies label the synaptic basal lamina (Fallon et al., 1985; Reist et al., 1987), a structure that in the absence of nerve can promote the formation of postsynaptic specializations on the surfaces of regenerating myofibers (Burden et al., 1979). Agrin immunoreactivity is present at the very earliest times that neuromuscular synapses can be identified in vivo (Godfrey et al., 1988; Fallon and Gelfman, 1989) and anti-agrin antisera can block the formation of nerve-induced AChR clusters on myotubes in culture (Reist et al., 1992). Also, recombinant agrin has been shown to induce the aggregation of muscle AChR (Campanelli et al., 1991; Tsim et al., 1992). Taken together, these observations provide strong evidence that agrin plays a

\footnotetext{
Received Aug. 18, 1992; revised Nov. 19, 1992; accepted Dec. 17, 1992.

We are grateful to $B$. McKechnie for expert technical assistance. We also thank Dr. K. Buckley for a gift of antibody. This work was supported by a postdoctoral fellowship from the Muscular Dystrophy Association (E.L.), NIH HD23924, and a Basil O'Connor Starter Scholar Research Award from the March of Dimes (J.R.F.).

Correspondence should be addressed to Erich Lieth, Department of Neurobiology, Harvard Medical Schonl, 220 Longwoad Avenue, Boston, MA 02115. Copyright $(1993$ Society for Neuroscience $0270-6474 / 93 / 132509-06 \$ 05.00 / 0$
}

pivotal role in orchestrating the formation of neuromuscular junctions, but the nature of that role remains to be elucidated.

Both ncural and muscle cells can synthesize agrin (MagillSolc and McMahan, 1988; Lieth et al., 1992), but it is not clear how agrin from these cellular sources may contribute to the formation of neuromuscular synapses. A simple model might state that agrin released from nerve endings causes synaptic elements to redistribute on the postsynaptic cell (McMahan, 1990). Another possibility is that axons induce the release of agrin and other related molecules from the muscle cells they contact, and that such molecules are involved in either the redistribution or stabilization of synaptic elements (Lieth et al., 1992). Also, agrin from muscle and nerve may act synergistically in the formation and maintenance of the neuromuscular junction. We have previously reported that muscle cells in culture synthesize and release agrin (Lieth et al., 1992). Moreover, these molecules are localized at $\mathrm{AChR}$ aggregates induced by agrin solubilized from Torpedo electric organ extracellular matrix. In the present study, we sought to characterize further the expression of muscle agrin at the neuromuscular junction to learn how this molecule may be involved in the formation of this synapse.

Ncuron-myotube cocultures provide a powerful and accessiblc system to study the role of agrin in synaptogenesis. Motoneurons induce the clustering of AChR on cultured myotubes, forming synapses that functionally and structurally resemble neuromuscular junctions in vivo (Anderson and Cohen, 1977; Frank and Fischbach, 1979; Cohen and Weldon, 1980; Role et al., 1987). Other neuronal types, such as cells of the dorsal root ganglia, lack this property. We cultured chick myotubes in the presence of motoneurons from rat spinal cord, and used speciesspecific antibodies that recognize chick agrin to visualize agrin derived from muscle. We show that muscle agrin colocalizes with nerve-induced $\mathrm{AChR}$ clusters. Furthermore, coculture with spinal cord cclls stimulates agrin expression by myotubes. We postulate that agrin derived from muscle cells contributes to the formation of stable postsynaptic specializations at the neuromuscular junction. These results demonstrate the existence of complex interactions between neurons and muscle cells that regulate the expression and spatial distribution of synaptic organizing molecules during neuromuscular junction development. The simple model of AChR clustering by neuronally released agrin is not sufficient to explain these findings. It seems more likely that both muscle and neuronal cells contribute actively to the formation and maintenance of junctions by secreting synapse organizing molecules.

\section{Materials and Methods}

Cell culture. Embryonic day 12 (E12) chick pectoral muscle was dissected, dissociated, and plated as described previously (Lieth et al., 

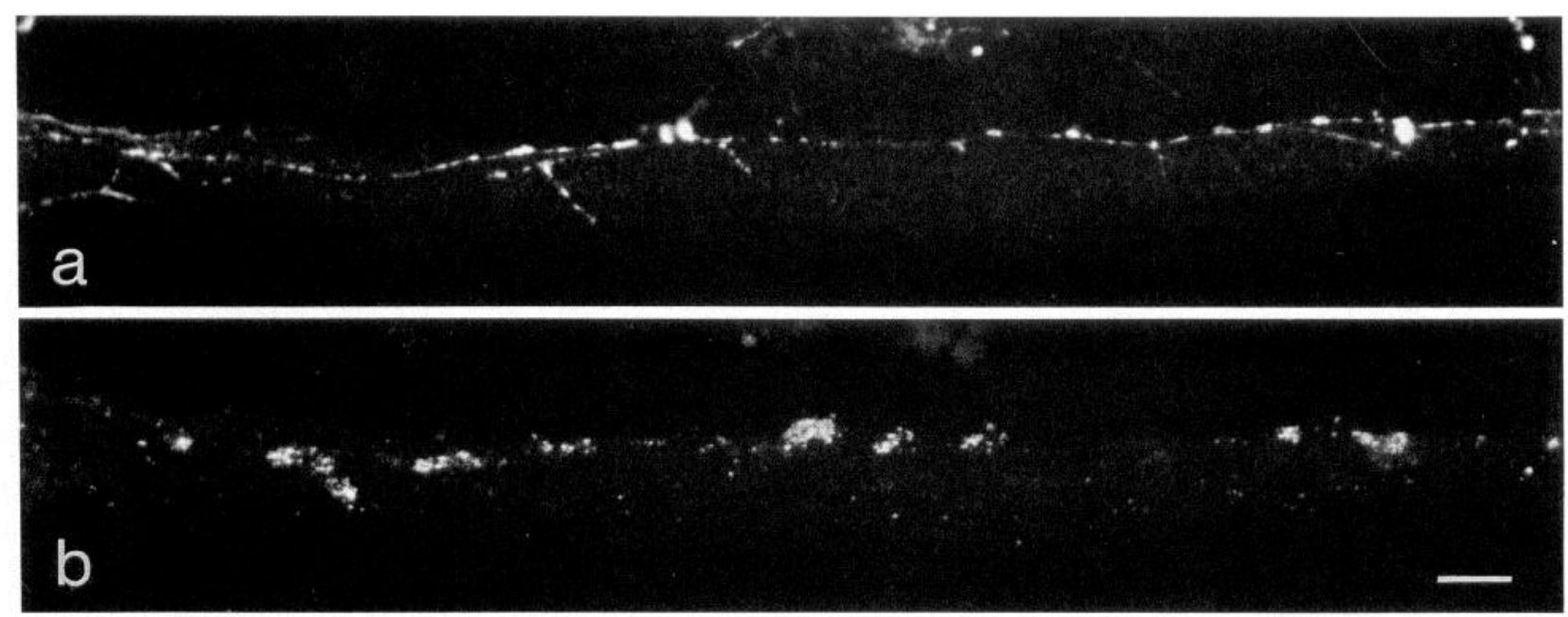

Figure 1. Coculture with rat ventral spinal cord neurons induces the patching of AChRs on the surfaces of chick myotubes. Four days after the addition of rat ventral spinal cord cells to chick muscle cell cultures, specimens were fixed and stained with rh-BTX and antibodies to the synaptic vesicle protein SV2. The same field is shown viewed in fluorescein and rhodamine optics to visualize neurites $(a)$ and $\mathrm{AChR}$ clusters $(b)$, respectively. Over $90 \%$ of AChR clusters were within $5 \mu \mathrm{m}$ of a neurite. Scale bar, $20 \mu \mathrm{m}$.

1992). One day later, E17 rat spinal cords were dissected and divided along the lateral sulcus into ventral and dorsal strips. Tissues were incubated in $0.25 \%$ trypsin for $30 \mathrm{~min}$ at $37^{\circ} \mathrm{C}$, mechanically dissociated, and transferred into a plating medium consisting of Dulbecco's modified Eagle's medium supplemented with $10 \%$ fetal bovine serum (FBS), penicillin, and glutamine. In order to maintain low baseline levels of muscle agrin expression, chick embryo extract was not used in these experiments. Cells were plated on preformed layers of chick myogenic cells at 100,000 cells/well in 96 -well plates for radioimmune assays or 50,000 cells/well on glass coverslips for immunocytochemistry. After $3 \mathrm{~d}$, cultures were fed by replacement with the same media. E1 7 cerebral cortex cultures were prepared exactly as described above. All animals were housed and handled in accordance with NIH guidelines.

Antibodies. The anti-agrin antibodies used here have been characterized extensively. Monoclonal antibodies (mAbs) 5B1 and 11D2 were raised against Torpedo agrin and cross-react with chick agrin. Their binding to agrin has been established using tissue sections, solubilized extracts, cell culture, immunoblots, and recombinant protein (Reist et al., 1987; Lieth et al., 1992; Ruegg et al., 1992). Both antibodies have been reported to be unreactive with rat agrin as judged by immunolabeling of tissue sections (Reist et al., 1987). We confirmed this lack of cross-reactivity in rat spinal cord cultured alone or together with primary rat muscle cells. In no case was any specific labeling observed. As these cultures were carried out in the presence of FBS, the lack of staining by $\mathrm{mAbs} 5 \mathrm{~B} 1$ and 11D2 also demonstrates either that FBS is free of agrin or that these antibodies do not recognize serum-borne bovine agrin. Thus, these antibodies are specific for agrin and suitable for the selective detection of chick agrin in rat/chick chimeric cultures.

Immunocytochemistry. Immunolabeling was performed exactly as described by Lieth et al., (1992). Briefly, cultures grown on glass coverslips were incubated in 5B1 hybridoma supernatant (approximately $20 \mu \mathrm{g}$ / $\mathrm{ml}$ specific IgG) followed by a fluorescein-conjugated goat anti-mouse Ig. AChRs were labeled using $5 \times 10^{-7} \mathrm{M}$ rhodamine-conjugated $\alpha$-bungarotoxin (rh-BTX; Molecular Probes, Eugene, OR) in the second layer. Cells were then fixed in $-20^{\circ} \mathrm{C} \mathrm{MeOH}$, mounted in Citifluor (Pella), and examined through a Zeiss Axioplan microscope equipped with epifluorescence optics. We obtained results indistinguishable from those reported here using another anti-agrin antibody, 11D2, whose species cross-reactivity is the same as that of $\mathrm{mAb} 5 \mathrm{~B} 1$ but that recognizes a different epitope. In some cultures, neurites were labeled with the antisynaptic vesicle antibody SV2 (Buckley et al., 1983). These cultures were first labeled with rh-BTX as described above, fixed for $5 \mathrm{~min}$ in $1 \% \mathrm{HCHO}$, and permeabilized with $0.05 \%$ saponin in PBS. The cells were then labeled with anti-SV2 followed by fluoresceinated secondary antibody as above.

Quantitation of immunocytochemical staining. To determine the colocalization of muscle agrin with AChR clusters, cultures were double labeled as described above. The number of $A C h R$ clusters $(\geq 2 \mu \mathrm{m}$ in any dimension) per $370 \mu \mathrm{m}$ myotube segment in each of 10 randomly selected microscope fields was determined under rhodamine optics. The colocalization of agrin immunoreactivity at these clusters was then determined by switching to the fluorescein-selective optics. The total number of AChR clusters and the proportion that colocalized with agrin were determined for at least two coverslips for each day in culture.

To compare the growth of neurites in cocultures of myotubes with either spinal cord or cortical cells, the number of myotube segments that exhibited zero, one, two, three, or four or more contacts with SV2labeled neurites were counted. For each condition, data gathered over the entire course of the experiment were pooled to identify differences between the culture conditions.

Solid-phase radioimmune assay. Radioimmune assays to measure muscle agrin expression were carried out as described (Lieth et al., 1992). Briefly, protein A-purified anti-agrin mAbs were labeled to $1.0-1.5 \times$ $10^{7} \mathrm{cpm} / \mu \mathrm{g} \mathrm{IgG}$ with ${ }^{125} \mathrm{I}$. The amount of agrin was measured by incubation with $1 \mu \mathrm{g} / \mathrm{ml}{ }^{125} \mathrm{I}$-anti-agrin. Nonspecific binding was determined by pre- and coincubation with 100 -fold excess unlabeled antibody. Each measurement is the average of six simultaneous determinations, adjusted for amount of protein in the individual cultures.

\section{Results}

Rat ventral spinal cord neurons induce AChR clusters on chick myotubes

The aggregation of AChRs on myotube surfaces by motoneurons in culture is commonly used as an indicator for the formation of nerve-muscle contacts (Anderson et al., 1977; Frank and Fischbach, 1979; Role et al., 1987). To induce the formation of postsynaptic specializations on chick myotubes, we added dissociated rat spinal cord cells. Figure $1, a$ and $b$, shows the colocalization of AChR clusters with neurites. We quantified this induction by measuring the number of AChR aggregates in cocultures with the motoneuron-rich ventral spinal cord as compared to cocultures with the motoneuron-poor cortex. Throughout the culture period, a greater number of AChR clusters is observed in cocultures with ventral cord neurons (Fig. 2). At 4 and $5 \mathrm{~d}$ in coculture, ventral spinal cord induced three to five times more AChR clusters as compared to cortex. The total number of clusters observed in ventral spinal cord cocultures was up to seven times greater than in muscle cultured alone (data not shown). We also quantitated the number of contacts between neurites and myotubes in each culture condition. Table 


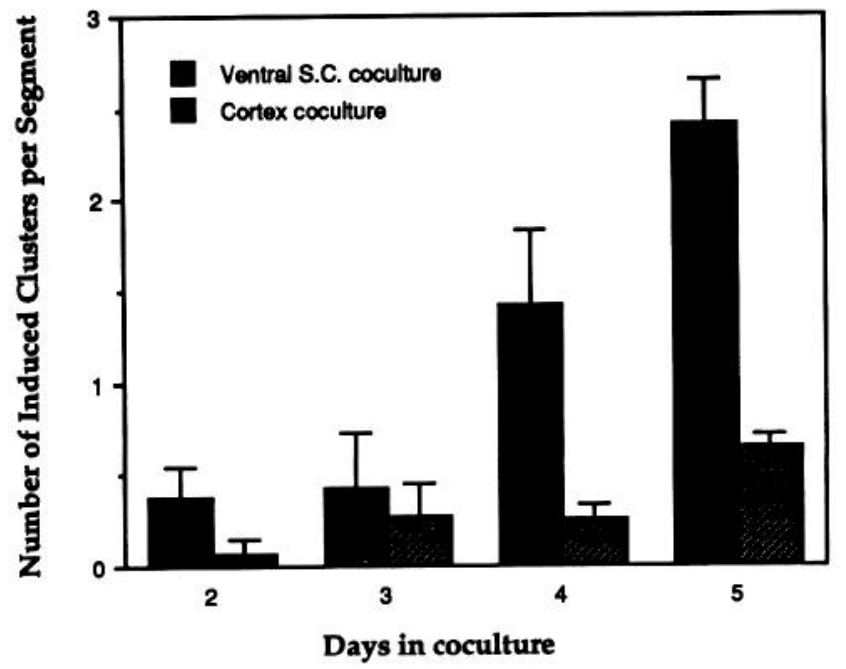

Figure 2. Ventral spinal cord neurons induce a greater number of AChR aggregates on myotubes than do cerebral cortical neurons. Neural cells were plated onto 1-d-old muscle cultures and the preparations stained 2-5 d later with rh-BTX. The number of AChR clusters per 370 $\mu \mathrm{m}$ myotube segment was counted as described in Materials and Methods. The number of nerve-induced AChR clusters was determined by subtracting the number of $\mathrm{AChR}$ clusters observed in same-age cultures grown without nerve (spontaneous clusters). Each determination is the mean of three cultures $( \pm$ SEM).

1 shows that there were equivalent numbers of neurite contacts in myotubes cultured with either spinal cord or cerebral cortical cells. The culture conditions used here thus provide comparable support for the growth of both neuronal types. Therefore, these results show that rat motoneurons selectively induce AChR clusters on chick myotubes.

\section{Muscle agrin accumulates at nerve-induced AChR clusters}

We previously showed that myogenic cells in culture secrete agrin-related molecules (Lieth et al., 1992). Here we studied the distribution of muscle agrin with respect to motoneuron-induced AChR aggregates. Chick myotubes and rat spinal cord neurons were cocultured and then stained with anti-agrin $\mathrm{mAb}$
Table 1. The number of neurite-myotube contacts is similar in myotubes cocultured with either cerebral cortical or spinal cord cells (see Materials and Methods)

\begin{tabular}{lll}
\multirow{2}{*}{$\begin{array}{l}\text { Number of } \\
\text { neurite } \\
\text { contacts }\end{array}$} & \multicolumn{2}{c}{ Number of myotube segments } \\
\cline { 2 - 3 } & Ventral spinal cord & Cortex \\
\hline 0 & 4 & 11 \\
1 & 23 & 12 \\
2 & 20 & 24 \\
3 & 10 & 12 \\
$\geq 4^{a}$ & 21 & 21 \\
\hline
\end{tabular}

${ }^{a}$ Four or more contacts per myotube segment.

$11 \mathrm{D} 2$ or 5B1. Both antibodies have previously been reported to bind chick, but not rat agrin (Reist et al., 1987). We confirmed this lack of cross-reactivity by labeling rat spinal cord cultured alone or together with primary rat muscle cells. In no case was any specific labeling observed (not shown). Thus, in these experiments only agrin secreted by muscle is visualized. Figure 3 shows the colocalization of muscle agrin with nerve-induced AChR clusters. Muscle agrin is concentrated at the large, mature AChR clusters. Note that the AChR microclusters $(\leq 2 \mu \mathrm{m})$ are not colocalized with muscle agrin. The accumulation of muscle agrin at the more developed AChR clusters is consistent with the hypothesis that it plays a role in the maturation or stabilization of these postsynaptic specializations (see Discussion).

To quantify the appearance of muscle agrin at nerve-induced AChR clusters, we compared the accumulation of agrin immunoreactivity at AChR clusters in cocultures containing motoneurons (ventral cord) to control cocultures without motoneurons (cerebral cortex). The number of agrin-colocalized AChR clusters increases steadily over time in coculture with ventral cord, but remains relatively unaltered in control cocultures (Fig. 4). By $5 \mathrm{~d}$ of culture up to 10 -fold more agrin-colocalized clusters are observed in ventral cord cocultures. The proportion of all AChR clusters that colocalize with muscle agrin is consistently high in ventral cord cocultures, particularly after $3 \mathrm{~d}$ in vitro (Fig. 4, numbers in bars). In cocultures with control neural cells this proportion varied between culture platings, similar to the
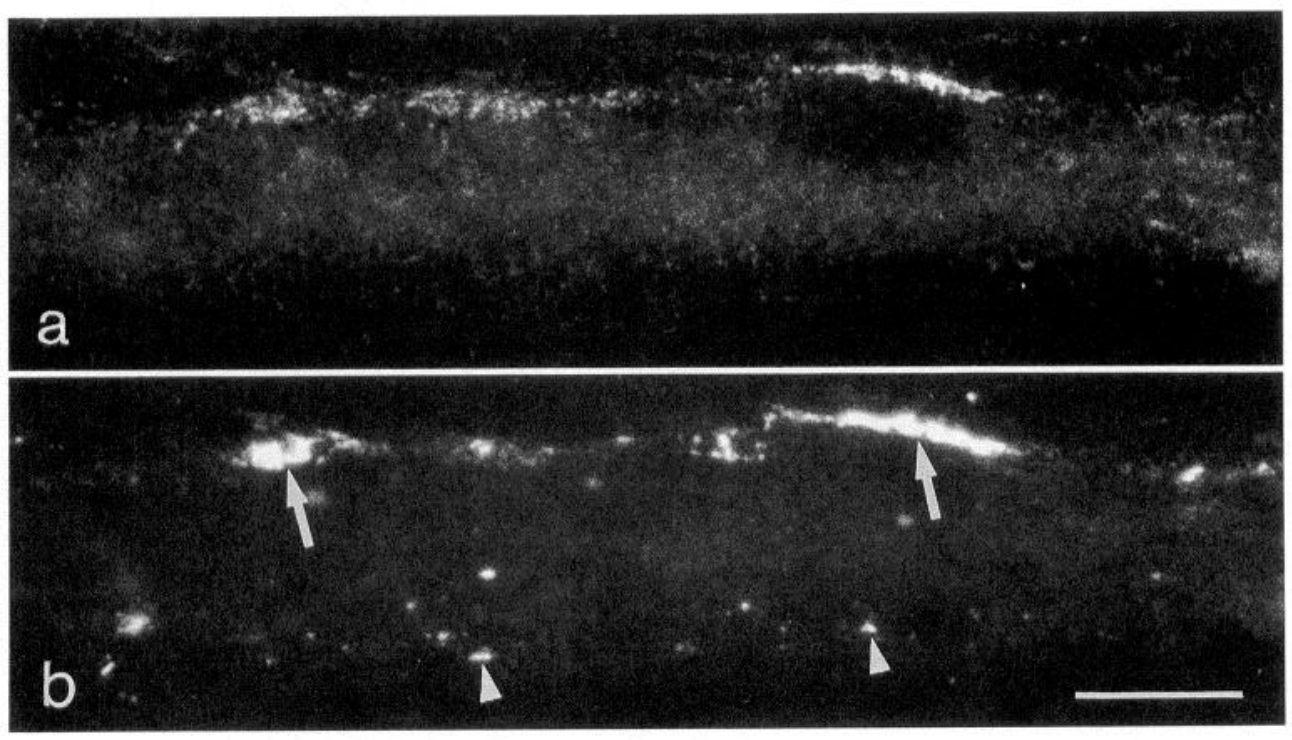

Figure 3. Muscle agrin colocalizes with nerve-induced $\mathrm{AChR}$ aggregates. Chick muscle cells were cultured with rat ventral spinal cord neurons for $3 \mathrm{~d}$, and then double labeled with anti-agrin antibody 5B1, which does not recognize rat agrin $(a)$ and rh-BTX $(b)$. Muscle agrin is concentrated at $87 \%$ (see Fig. 4) of the large, mature AChR clusters (arrows). Note that the AChR microclusters $(\leq 2 \mu \mathrm{m}$, arrowheads) are not colocalized with muscle agrin. Scale bar, $10 \mu \mathrm{m}$. 


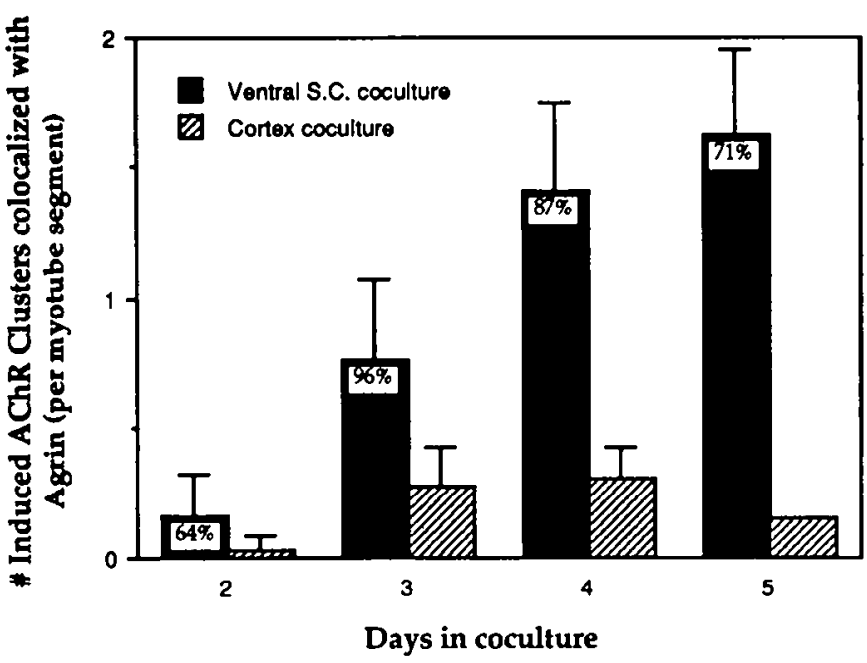

Figure 4. At all days in vitro ventral spinal cord cells induce a grcater number of agrin-colocalizing $\mathrm{AChR}$ clusters than do cortical cells. Chick myotubes were cultured for 2-5 d in the presence of rat ventral spinal cord or cerebral cortex cells. Preparations were stained with rh-BTX and $\mathrm{mAb} 5 \mathrm{~B} 1$, and the number of AChR patches colocalized with muscle agrin counted. Each determination is the mean ( \pm SEM), adjusted for the number of agrin-colocalizing spontancous clusters. Numbers inside bars are the percentages of all AChR clusters in the cultures that were also colocalized with muscle agrin.

variable colocalization with spontaneous $A C h R$ clusters observed in cultures of myotubes alone (Lieth et al., 1992). In cocultures containing motoneurons, the percentage of colocalized AChR clusters was always at least $70 \%$ by $3 \mathrm{~d}$ in vitro. Thus, agrin derived from muscle accumulates at a high proportion of AChR clusters induced by neurons of the ventral spinal cord.

\section{Spinal cord neurons stimulate the expression of muscle agrin}

The colocalization of muscle agrin with nerve-induced AChR aggregates opens the possibility that muscle responds to the presence of motoneurons by secreting increased amounts of agrin. We therefore measured the effect of spinal cord coculture on the accumulation of muscle agrin. Muscle agrin levels were determined by radioimmunoassay. Coculture with rat ventral spinal cord increased the expression of muscle agrin by more than twofold as compared to myotubes cultured alone (Fig. 5). In contrast, only a small increase was observed after coculture with cerebral cortical cells. The overall protein levels in these cultures was not affected by coculture with neural cells (data not shown). These results indicate that the motoneuron-rich spinal cord selectively increases the expression of muscle agrin.

\section{Discussion}

The studies reported here were designed to assess the expression of muscle agrin at nerve-induced AChR clusters. We show that rat spinal cord cells induce AChR clusters on cultured chick myotubes, and that agrin synthesized by the muscle cells is concentrated at these postsynaptic specializations. In addition, coculture with spinal cord cells induces an increase in the expression of muscle agrin. These findings suggest that the agrin localized at the neuromuscular junction is synthesized at least in part by the muscle cell, and indicate that the expression of muscle agrin is regulated by interaction with neurons.

Agrin synthesis by muscle cells is well cstablished (Fallon and

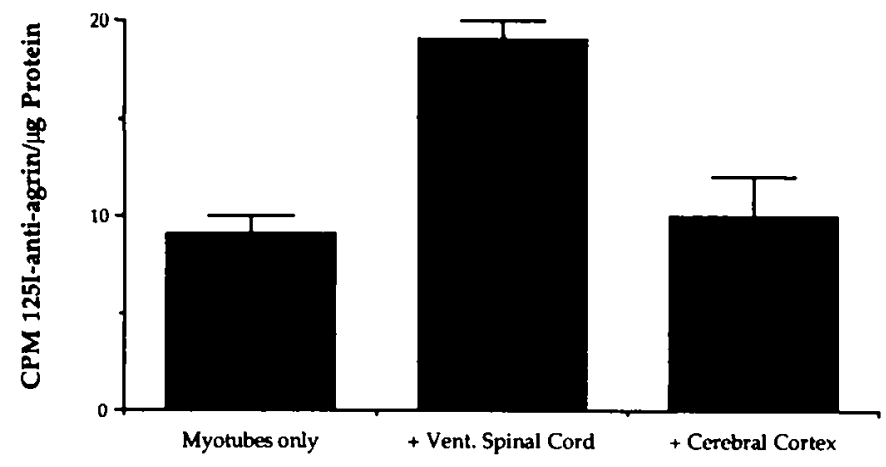

Figure 5. Coculture with ventral spinal cord stimulates the expression of agrin by muscle cells. Chick myotubes were cultured either alone, with rat ventral spinal cord cells, or with cerebral cortex cells for $5 \mathrm{~d}$. Agrin was measured by radioimmunoassay using $\mathrm{mAb} 5 \mathrm{Bl}$, which in these cultures recognizes only agrin expressed by muscle. Each determination represents the mean of six cultures normalized for total protein/culture $( \pm S D)$. Ventral spinal cord culture increased the amount of muscle agrin by twofold as compared to coculture with cerebral cortex or myotubes alone. Ventral spinal cord versus myotube alone, $p<0.001$; ventral spinal cord versus cortical coculture, $p<0.01$ (Student's $t$ test).

Gelfman, 1989; Lieth et al., 1989, 1992; Ruegg et al., 1992). However, in none of these studies could it be determined if muscle agrin is expressed at the neuromuscular junction. We therefore designed a chimeric nerve-muscle coculture system to address this question. Dissociated rat ventral spinal cord cells induce robust AChR clustering on chick myotubes, but cerebral cortical cells (Figs. 1, 2), dorsal spinal cord, or sensory ganglia (E. Lieth and J. R. Fallon, unpublished observations) do not. This clustering is similar to that seen when chick spinal or parasympathetic motoneurons are cocultured with myotubes (Frank and Fischbach, 1979; Role et al., 1987). In the present study, greater than $90 \%$ of clusters in nerve-muscle cocultures were associated with neurites (Fig. 1), indicating that neurons induced AChR clusters in our cultures. As shown in Figure 3, muscle agrin is localized at the nerve-induced AChR clusters.

In a recent study using a chimeric frog system, Cohen and Godfrey (1992) did not detect the expression of muscle agrin at ncurite contacts. It is not known whether the failure to detect muscle agrin in this case is due to insufficiently sensitive detection methods or the lack of muscle agrin expression by these amphibian cells. Significantly, muscle agrin was not observed under any circumstances in the frog experiments. It is important to determine whether this contrasting result is due to technical or species differences. It should be noted that agrin protein and mRNA are expressed in avian and mammalian muscle, as well as in elasmobranch electric organ (Lieth et al., 1992; Ruegg et al., 1992; Smith et al., 1992). Thus, agrin expression by the targets of motoneurons is well conserved in evolution, and the failure of frog muscle to express agrin would be a departure from this observation. On the other hand, the detection of muscle agrin at nerve-induced AChR clusters is in accord with earlier work demonstrating muscle agrin localization at spontaneous and Torpedo agrin-induced AChR clusters (Fallon and Gelfman, 1989; Lieth et al., 1992). Thus, muscle agrin is localized at AChR clusters that arise in at least three different contexts.

The stimulation of muscle agrin accumulation by spinal cord cells (Fig. 5) is of considerable interest since it suggests the motoncuron may regulate the expression of target-derived agrin at the synapse. Although the mechanism of this stimulation is 
unknown, one attractive and economical model is suggested by recent data. We have previously demonstrated that the cell surface receptor for exogenous Torpedo agrin is distinct from the AChR (Nastuk et al., 1991). Both this receptor as well as the AChRs redistribute in response to incubation with exogenous agrin. Moreover, newly synthesized muscle agrin selectively accumulates at AChR clusters induced by Torpedo agrin (Lieth et al., 1992). These observations, coupled with the tyrosine phosphorylation of the AChRs seen upon agrin stimulation (Wallace et al., 1991), suggest that exogenous agrin activates a series of intracellular events that mediate the formation of postsynaptic specializations. It is tempting to speculate that the stimulation of agrin expression in muscle cells is one of the events evoked by neurally derived agrin during the formation of neuromuscular junctions. It is of course also possible that electrical activity or neuronally derived factors such as $\mathrm{ACh}$ receptor-inducing activity (ARIA) calcitonin gene-related peptide could induce the expression of muscle agrin (New and Mudge, 1986; Usdin and Fischbach, 1986; Rutishauser and Landmesser, 1991). Furthermore, while there is good evidence that motoneurons regulate the expression of muscle-derived agrin, we cannot rule out the possibility that non-neuronal cells from the spinal cord may contribute to this regulation. We are currently testing these hypotheses.

Recent molecular analysis of agrin has revealed that agrin isoforms arise by alternative mRNA splicing. Studies using recombinant fragments of chick agrin indicate that only the isoforms expressed by motoneurons induce AChR clustering (Ruegg et al., 1992). On the other hand, all full-length isoforms of rat agrin can stimulate AChR aggregation (Ferns et al., 1992). While the reasons for this apparent discrepancy remain to be clucidated, it is clear that isoforms of agrin expressed by muscle are capable of inducing AChR aggregation.

It has recently been reported that neuronally derived agrin is present at AChR clusters in Xenopus/Rana cocultures (Cohen and Godfrey, 1992). In preliminary studies with chick ciliary ganglion neurons cultured on rat myotubes, we have found that neural agrin is localized at AChR clusters (Lieth and Fallon, unpublished observations). In addition, motoneurons synthesize agrin and transport it anterogradely (Magill-Solc and McMahan, 1988), and antisera specific for chick agrin partially block AChR cluster induction in chick ciliary ganglion/rat muscle cultures (Reist et al., 1992). Taken together with the present results, these data indicate that there is a dual cellular origin of agrin at the neuromuscular junction.

We propose that this dual origin is a reflection and a mediator of the critical cellular interactions underlying synaptogenesis. The formation of the neuromuscular junction is a lengthy, complex process. Over 7 weeks elapse between the time that nerveinduced AChR clusters first appear to the point at which the synapse is fully mature (reviewed in Salpeter, 1987; see also Dahm and Landmesser, 1991). Sevcral major events occur in the intervening period including motoneuron cell death, formation and innervation of secondary myotubes, climination of polyneuronal innervation, and metabolic stabilization of $\mathrm{AChR}$ turnover. Thus, there are numerous points during synaptogenesis in which muscle agrin may play a role, and these events are not limited to the initial events in nerve-induced AChR clustering.

A model for agrin expression suggested by these studies is that neurally derived agrin is released onto the muscle cell surface and induces the initial formation of postsynaptic structures.
This exogenous, neuronally derived agrin would then signal the expression of muscle agrin at these specializations. This model is consistent with the observation that muscle agrin alone induces only low levels of AChR clustering (Godfrey, 1991; Lieth et al., 1992), and that antisera specific to neuronal agrin incompletely block nerve-induced clustering (Reist et al., 1992). As discussed previously, this endogenous muscle agrin could be part of the machinery intrinsic to the myofiber that is necessary for it to organize its postsynaptic apparatus. For example, muscle agrin could serve to stabilize the postsynaptic specialization (Licth et al., 1992). A key to understanding the respective functions of agrin derived from these different cells is to identify the isoforms present at each stage in synapse development. Such a temporal characterization is essential since, for example, tyrosine phosphorylation of the AChR is only observed after birth in the rat, even though AChR clustering and agrin accumulation are seen a week carlier (Qu et al., 1990; Rupp et al., 1991). It is also important to characterize fully the agrin receptor at these developing junctions; work on this problem is in progress (Nastuk et al., 1991). Finally, additional assays need to be brought to bear in order to probe selectively the different stages of AChR formation and stabilization.

In summary, we have shown that the expression and localization of muscle agrin are subject to neural regulation. The dual source of agrin at the neuromuscular junction, coupled with the existence of this regulatory network, suggests that neuronal agrin alone does not direct all aspects of postsynaptic differentiation. More likely, agrin from both the neuron and muscle collaborate to organize the nerve-muscle synapse.

\section{References}

Anderson MJ, Cohen MW (1977) Nerve-induced and spontaneous redistribution of acetylcholine receptors on cultured muscle cells. J Physiol (Lond) 268:757-773.

Buckley KM, Schweitzer ES, Miljanich GP, Clift OL, Kushner PD, Reichardt LF, Kelly RB (1983) A synaptic vesicle antigen is restricted to the junctional region of the presynaptic plasma membrane. Proc Natl Acad Sci USA 80:7342-7346.

Burden SJ, Sargent PB. McMahan UJ (1979) Acetylcholine receptors in regenerating muscle accumulate at original synaptic sites in the absence of the nerve. J Cell Biol 82:412-425.

Campanelli JT, Hoch W, Rupp F, Kreiner T, Scheller RH (1991) Agrin mediates cell contact-induced acetylcholine receptor clustering. Cell 67:909-916.

Cohen MW, Godfrey E (1992) Early appearance of and neuronal contribution to agrin-like molecules at embryonic frog nerve-muscle synapses formed in culture. J Neurosci 12:2982-2992.

Cohen MW, Weldon PR (1980) Localization of acctylcholine receptors and synaptic ultrastructure at nerve-muscle contacts in culture: dependence on nerve type. J Cell Biol 86:388-401.

Dahm LM, Landmesser LT (1991) The regulation of synaptogenesis during normal development and following activity blockade. J Neurosci 11:238-255.

Fallon JR, Gelfman CE (1989) Agrin-related molecules are concentrated at acetylcholine receptor clusters in normal and aneural developing muscle. J Cell Biol 108:1527-1535.

Fallon JR, Nitkin RM, Reist NE, Wallace BG, McMahan UJ (1985) Acetylcholine receptor-aggregating factor is similar to molecules concentrated at neuromuscular junctions. Nature 315:571-574.

Ferns MJ, Hoch W, Rupp F, Kreiner T, Scheller RH (1992) RNA splicing regulates agrin-mediated acetylcholine receptor clustering activity on cultured myotubes. Neuron 8:1079-1086.

Frank E, Fischbach GD (1979) Early events in neuromuscular junction formation in vitro: induction of acetylcholine receptor clusters in the postsynaptic membrane and morphology of newly formed synapses. J Cell Biol 83:143-158.

Godfrey EW (1991) Comparison of agrin-like proteins from the ex- 
tracellular matrix of chicken kidney and muscle with neural agrin, a synapse organizing protein. Exp Cell Res 195:99-109.

Godfrey EW, Siebenlist RE, Wallskog PA, Walters LM, Bolender DL, Yorde DE (1988) Basal lamina components are concentrated in premuscle masses and at early acetylcholine receptor clusters in chick embryo hindlimb muscles. Dev Biol 130:471-486.

Lieth E, Missias AC, Yang E, Fallon JR (1989) Agrin-related molecules at the developing neuromuscular junction. The assembly of the nervous system. New York: Liss.

Lieth E, Cardasis CA, Fallon JR (1992) Muscle-derived agrin in cultured myotubes: expression in the basal lamina and at induced acetylcholine receptor clusters. Dev Biol 149:41-54.

Magill-Solc C, McMahan UJ (1988) Motor neurons contain agrin-like molecules. J Cell Biol 107:1825-1833.

McMahan UJ (1990) The agrin hypothesis. Cold Spring Harbor Symp Quant Biol 50:407-418.

Nastuk MA, Fallon JR (1993) Agrin and the molecular choreography of synapse formation. Trends Neurosci 16:72-76.

Nastuk MA, Lieth E, Ma J, Cardaisis CA, Moynihan EB, McKechnie BA, Fallon JR (1991) The putative agrin receptor binds ligand in a calcium-dependent manner and aggregates during agrin-induced acetylcholine receptor clustering. Neuron 7:807-818.

New HV, Mudge AW (1986) Calcitonin gene-related peptide regulates Ach R synthesis. Nature 323:809-811.

Nitkin RM, Smith MA, Magill C, Fallon JR, Yao YM, Wallace BG, McMahan UJ (1987) Identification of agrin, a synaptic organizing protein from Torpedo electric organ. J Cell Biol 105:2471-2478.

Qu ZC, Moritz E, Huganir RL (1990) Regulation of tyrosine phosphorylation of the nicotinic receptor at the rat neuromuscular junction. Neuron 4:367-378.

Reist NE, Magill C, McMahan UJ (1987) Agrin-like molecules at synaptic sites in normal, denervated, and damaged skeletal muscles. J Cell Biol 105:2457-2469.

Reist NE, Werle MJ, McMahan UJ (1992) Agrin relcased by motor neurons induces the aggregation of acetylcholine receptors at neuromuscular junctions. Neuron 8:865-868.

Role LW, Roufa DG, Fischbach GD (1987) The distribution of acetylcholine receptor clusters and sites of transmitter release along chick ciliary ganglion neurite-myotube contacts in culture. J Cell Biol 104: 371-379.

Ruegg MA, Tsim KW, Horton SE, Kroeger S, Escher G, Gensch EM, McMahan UJ (1992) The agrin gene codes for a family of basal lamina proteins that differ in function and distribution. Neuron 8:691699.

Rupp F, Payan DG, Magill-Solc C, Cowan DM, Scheller RH (1991) Structure and expression of a rat agrin. 6:811-823.

Rutishauser U, Landmesser L (1991) Polysialic acid on the surface of axons regulates patterns of and activity-dependent innervation. Trends Neurosci 14:528-532.

Salpeter MM (1987) Development and neural control of the neuromuscular junction and of the junctional acetylcholine receptor. In: The vertebrate neuromuscular junction (Salpeter MM, ed), pp 55115. New York: Liss.

Smith MA, Magill-Solc C, Rupp F, Yao YM, Schilling JW, Snow P, McMahan UJ (1992) Isolation and characterization of a cDNA that encodes an agrin homologue in marine ray. Mol Cell Neurosci 3:406417.

Tsim KW, Ruegg MA, Escher G, Kroeger S, McMahan UJ (1992) cDNA that encodes active agrin. Neuron 8:677-689.

Usdin TB, Fischbach GD (1986) Purification and characterization of a polypeptide from chick brain that promotes the accumulation of acetylcholine receptors in chick myotubes. J Cell Biol 103:493-507.

Wallace BG (1989) Agrin-induced specializations contain cytoplasmic, membrane, and extracellular matrix-associated components of the postsynaptic apparatus. J Neurosci 9:1294-1302.

Wallace BG, Qu Z, Huganir RL (1991) Agrin induces phosphorylation of the nicotinic acetylcholine receptor. Neuron 6:869-878. 